\title{
The Role of Communication Apprehension and Self- Stigma of Academic Help-Seeking in Native and Non- native English Speakers: Evidence from UK University Students
}

\author{
Marta Sobotka ${ }^{1} \&$ Ilhan Raman ${ }^{2, *}$ \\ ${ }^{1}$ Middlesex University, The Burroughs, Hendon, London NW4 4BT, UK \\ ${ }^{2}$ Department of Psychology, Middlesex University, The Burroughs, Hendon, London NW4 \\ 4BT, UK \\ *Corresponding author: Middlesex University, The Burroughs, Hendon, London NW4 4BT, \\ UK.E-mail:m.sobotka@mdx.ac.uk
}

Received: July 15, 2020 Accepted: August 14, 2020 Published: August 28, 2020

doi:10.5296/ije.v12i3.17355 URL: https://doi.org/10.5296/ije.v12i3.17355

\begin{abstract}
Although communication apprehension (CA) has long been reported to hinder communication skills and academic attainment, its cumulative impact on self-stigma of academic help-seeking in a global education market has nevertheless been overlooked. The present study examined the relationship between CA and self-stigma of academic help-seeking among British university students who acquired English at different stages in their lives and its impact on achievement. Data were collected from 150 students who completed the Personal Report of Communication Apprehension (PRCA-24) and the self-stigma of academic help-seeking scale together with a demographic questionnaire. Overall, the findings showed a significant relationship between CA and self-stigma of academic help-seeking while age of English acquisition, residency status and level of study were also found to have a significant effect on the level of CA. The implications of the results are discussed within the higher education provision, pedagogy and psychological frameworks.
\end{abstract}

Keywords: communication apprehension (CA), higher education, English as second language (ESL), English as foreign language (EFL), English as additional language (EAL), internationalisation, self-stigma of academic help-seeking 


\section{Introduction}

Effective communication skills are highly desired tools across a wide range of professions and for improving career prospects that lead to their integration into the mainstream curriculum by higher education institutions (HEIs) (Blume, Baldwin, \& Ryan, 2013; Croucher, 2017; Sabri \& Qin, 2014). Additionally, evidence suggests that employers put communication skills on top of their agenda in recruiting their employees (Byrne, Flood, \& Shanahan, 2012) subsequently putting HEIs under increased pressure to endow students with communication skills that would allow them to compete in a global market of employment. However, incorporating communication skills training in a given curriculum is simply not sufficient to improve skills among all students (Allen \& Bourhis, 1996). Although several factors could be at play, one of the main reasons for failing to achieve high levels of communication skills is attributed to Communication Apprehension (CA) introduced by McCroskey (1970) and defined as 'an individual's level of fear and anxiety associated with either real or anticipated communication with another person' (McCroskey, 1977, p. 78).

\subsection{Literature Review}

Historically, research concerned with fear of communication has been discussed in the literature since the beginning of the $20^{\text {th }}$ century while the concept of CA (McCroskey, 1970) has become the widely accepted operational definition for research (Blume et al., 2013; McCroskey, 2009; Rahmani \& Croucher, 2017). Simply put, the relationship between CA and activities related to communication in all its forms is inverse, in that, as apprehension increases activities and/or performance decrease. Previous reports show that during classes, anxious learners are likely to freeze up in role-play activities or debates, forget previously learned material, avoid participation in class discussions, and are less likely to volunteer answers in comparison to their non-anxious fellow classmates (Horwitz, Horwitz, \& Cope, 1986; McCroskey, 1982). Avoidance behaviours such as nonattendance to classes and/or procrastinating on coursework also become more prevalent (Gregersen \& Horwitz, 2002). The consensus is that $\mathrm{CA}$ has serious implications on educational outcomes, ranging from reduced participation in class, to low achievement (Elkhafaifi, 2005), to class avoidance (Brown, 2008; Horwitz et al., 1986) and even to dropping out from courses (Dewaele \& Thirtle, 2009). Collectively the findings suggest that meaningful changes to curricula are essential in order to prevent or reduce the negative impact of CA.

Insofar as a globalised world is concerned, the emphasis is not solely on the importance of communication skills but also on the need for raising awareness of growing internationalisation of HEIs (Andrade, 2006; Brown, 2008; Croucher, 2017). In spite of a globalised trend in HEIs since the previous century, studies tend to overlook student diversity and hence ignore the rather heterogenous nature of class membership (Pappamihiel, 2001). In this respect, internationalisation of HEIs necessitates a closer examination of students with different educational, linguistic and cultural backgrounds even when English language is the common denominator (Williams, 2005). This is especially important where English is L2, given L2 speakers can be categorised into several groups depending on multiple social and linguistic factors (Raman \& Y1ldiz, 2019). The concept of CA does not only refer to a fear of 
communicating in one's native language (L1) but is also applicable to foreign language learning and usage in a second language (L2) (Richmond, McCroskey, McCroskey, \& Fayer, 2008). According to Sabri and Qin (2014) CA is higher among non-native or L2 speakers.

The role of age of acquisition on the ultimate achievement of a second or foreign language proficiency has been debated for years (Chomsky, 1972). Although CA research typically focuses on classroom-based anxiety (Horwtiz et al., 1986; MacIntyre \& Gardener, 1991), understanding anxiety outside the classroom has gained recent attention by focusing on immigrants experiencing language anxiety in their second language in real-life situations (Garcia de Blakeley, Ford, \& Caseya, 2017). Nevertheless, the impact of changing language learning environments on students, in particular, from learning English as a Foreign language (EFL) to mainstream English is understudied particularly in the UK context (Lillyman \& Bennett, 2014; Pappamihiel, 2001). It must be stressed that language anxiety has been shown to equally affect EFL students in a foreign language classroom as does English as a Second Language (ESL) students in mainstream classrooms (Pappamihiel, 2001; Sung, 2014). This is more pronounced in academic contexts when students are exposed to academic English. Typically, EFL and ESL students tend to be omitted in CA studies as they are likely to be considered proficient in English. According to Cummins (1979) although ESL students are likely to achieve Basic Interpersonal Communicative Skills (BICS) within two years, some learners may need five to seven years or longer to achieve cognitive academic language proficiency (CALP) equivalent to monolingual English speakers. The unidentified discrepancy between ESL/EFL and BICS is probably one of the main contributing factors of the CA problem in HEIs. The lack of a graded transition of using academic English from ESL/EFL to CALP level of competence in mainstream education can be argued to lead to high levels of anxiety especially in the presence of native English speakers, as the expectations and the level of English used in class are presumably higher than ESL/EFL levels. Students from ESL/EFL backgrounds are typically reported to be more anxious over speaking than any other communication skill (Noor, Rafek, Khalid, \& Mohammad, 2015). Nayeem, Khan and Mehta's (2015) study on 130 pharmacy students revealed that $70 \%$ of students are communication apprehensive due to language issues. Furthermore, another study of 24 students using the university's language of instruction at a different level revealed that the level of language has an impact on CA among students (Rasakumaran \& Devi, 2017). Dewaele and Shan Ip (2013) suggested that students learning an L2 language before formal education starts are less anxious than those who start L2 learning later through classroom instruction. Therefore, more research is needed to understand CA in native students and non-native students learning English but also in English speakers using this language as a second or additional language in mainstream classroom settings.

While age was not explicitly identified in the formation of CA, McCroskey (1977) suggested that CA develops during early childhood and possibly diminishes over time. Studies considering this demonstrated that the level/year of study can affect CA with first and second year students reporting higher CA than those in their final years of study (Nayeem et al., 2015). The study conducted by Alkhateeb (2014) showed similar results with significantly more anxious students being in their earlier years of study. Onwuegbuzie, Bailey and Daley (1999) also demonstrated that there was a positive correlation between levels of CA and level of study. 
Although these findings provide support to the notion that CA decreases over time, an inconsistent finding was reported by Hassall, Joyce, Ottewill, Arquero and Donoso (2000) indicating a non-significant relationship between level of study and CA. The nature of the relationship between CA and age is a controversial one with contradictory findings such that both a positive relationship (Dewaele \& Shan Ip, 2013) and a negative relationship are reported in the literature (Donovan \& MacIntyre, 2004). A recent study with 157 students also found no evidence of age on CA (Rahmani \& Croucher, 2017) and similar findings were reported on Spanish and British students with no effect of age on CA (Hassall et al., 2000). The reasons for the inconsistency in the findings could be numerous, some of which could be the diversity of teaching techniques used across HEIs, learning styles, motivation and general affective filter amongst others.

On one hand, CA and language anxiety claimed to be related to the inner self(Abu-Rabia, 2004) and therefore psychologically it may challenge one's self-concept as a capable communicator, and depending on outcomes, lead to fear (Horwitz et al., 1986). On the other hand, academic help-seeking is a significant self-regulatory approach that contributes to student learning and is positively correlated with achievement (Newman, 2002; Ryan, Gheen, \& Midgley, 1998). Similarly, CA is linked to student achievement and many communication skills classes are focused on training those skills by including presentation and speaking tasks and encouraging learners to be active in asking questions (Raphael \& Pearson, 1985). Although research emphasises the significance of questioning in the classroom (Pearson \& West, 1991), the relationship between $\mathrm{CA}$ and help-seeking behaviours is nevertheless being underestimated and little research has been done on this topic (Arquero, Hassall, Joyce, \& Donoso, 2007). Reports also suggest that educators who are concerned with potentially making students more apprehensive end up ignoring 'the quiet' students and do not encourage them to be engaged in class activities (Aitken \& Neer, 1993).

Self-stigma of academic help-seeking refers to 'thinking process in which negative selfjudgments or fears of negative judgments from others do not allow students to seek academic help' (p. 21) and was first proposed by Winograd and Rust (2014) based upon Vogel, Wade, and Haake's (2006) work on self-stigma in help seeking in mental health services. Similarly, students with CA tend to feel embarrassed to raise questions in class due to a fear of being misunderstood and/or judged by a tutor and peers often making them feel too uncomfortable to speak (Semmar, 2010). An observation made by McCroskey (1977) is relevant here in that individuals with high CA are most likely to avoid communication mainly in public speaking or seeing an advisor. This is particularly important when it comes to asking for academic help. Similarly, it has been reported that individuals with high CA avoid self-disclosure conversations and are unlikely to seek assistance from tutors (Scott \& Wheeless, 1977). McCroskey and Andersen (1976) further noted that establishing good communication between students and tutors, including questioning and help-seeking, is essential to achieve academic success. It is envisaged here that exploring the relationship between CA and self-stigma of academic help-seeking will lead to reviewing and changing HEIs approach towards students with CA and the development of effective pedagogy and support in this regard.

The role of proficiency and age of acquisition on L2 have been demonstrated to influence not 
only the behavioural aspects but also the way the bilingual brain becomes neuronally activated (Perani, Paulesu, Galles, Dupoux, Dehaeneet al, 1998). The effect of early and late acquisition of L2 in highly proficient bilinguals were examined in an fMRI study in two groups of participants: a) Italian-English bilinguals who acquired L2 after the age of 10 years (late L2) and b) Spanish-Catalan bilinguals who acquired L2 before the age of 4 years (early L2). Perani et al (1998) reported that 'for pairs of L1 and L2 languages that are fairly close, attained proficiency is more important than age of acquisition as a determinant of the cortical representation of L2'. In the context of HEIs, age of acquisition of L2 (i.e., English) remains an important factor such that irrespective of level of CA, participants are found to have some degree of anxiety while they speak in L2 in front of others (Bijani \& Sedaghat, 2016). Moreover, linguistic differences between L1 and L2 have been found to raise CA and more importantly raise avoidance behaviours of academic help-seeking (Rahmani \& Croucher, 2017). Additionally, individuals from ethnic minority communities often feel intimidated when seeking help due to fear of being rejected or judged (Winograd \& Rust, 2014). Interestingly, international students tend to use avoidance strategies principally in the first few weeks, typically during the first week, of the academic year (Lillyman \& Bennett, 2014). Those findings suggest that residency status, whether Home, EU or International, may influence selfstigma of academic help-seeking. One of the aims of the present study is to explore this further by taking the residency status of students into account in relation to CA and self-stigma of academic help-seeking.

\subsection{Rationale for the Current Study}

The rationale for the current study is motivated to bring together two distinct areas of research, namely CA and self-stigma of academic help seeking. The main objective is to address an existing gap in the literature by taking into consideration CA as an entity that can affect a) native English speakers and also b) non-native English speakers using English as either a second language (ESL) or c) an additional language (EAL) in the same classroom.

Based on the literature review above, even though it is evident that much CA research was conducted on native and non-native English speakers, little has been reported on the relationship between these two concepts. Additionally, previous research tends to focus either on native speakers or EFL students, not measuring the effects of CA on students in mixed classes (Lillyman \& Bennett, 2014; Pappamihiel, 2001).

The relationship between CA and academic help-seeking behaviours will be further explored by including students with a wide range of age of L1 and L2 English acquisition and different residency status (Home/UK, EU, International) in order to better understand the pedagogic implications in the classroom. Given the steady rise in the number of international students studying in the UK since the 1990s with a significantly higher number based in London HEIs (Brown, 2008), residency forms an important aspect of the current study. It is predicted that $\mathrm{CA}$ and self-stigma of academic help-seeking will be associated in the current study as well as age of the participants.

It is envisaged that the results of the current study will be of interest to educators, psychologists, students and HEIs management sector as development of appropriate and effective curricular 
and pedagogic strategies reducing CA across all communication contexts and self-stigma of academic help-seeking has the potential to reduce number of students dropping out of their courses and also to improve academic performance (McCroskey, 1977; Winograd \& Rust, 2014).

\section{Method}

\subsection{Design}

The study employed a quasi-experimental design using standardised questionnaires together with a demographic questionnaire in a 3 (residency status: home, EU, international) x 3 (age of English language acquisition: early, late before puberty, late after puberty) x 4 (age: 18-20, 21-24, 25-28, 29+) x 5 (level of study: Year 1, Year 2, Year 3, Master's, PhD) between-subjects factorial design. The dependent variables were the scores on the questionnaires.

\subsection{Participants}

A total number of 157 university students in London with different levels of study were recruited for the purpose of the study. Seven participants failed to complete some of the relevant items, leaving an analysis sample of 150 of which 123 (82\%) participants were female and 27 (18\%) male. 82 students (54.7\%) were between 21 and 24 years old, 46 students $(30.7 \%)$ were between 18 and 20 years old, 12 students $(8 \%)$ were between 25 and 28 years old and 10 students $(6.7 \%)$ were either 29 years old or older. The participants were divided into three different groups on the basis of their age when they started learning English. Given that the lateralisation of receptive language function is assumed to be fully established by the age of 5 (Krashen \& Harshman, 1972), a group of participants were English speakers who started learning English before the age of 5, considered as a chronological cut-off date. The second group included English speakers who acquired that language later than the first group but before the onset of puberty, which according to the critical period hypothesis is the cut-off for language to develop fully on a native level (Lenneberg, 1967). The last group consisted of English speakers who acquired English language skills late, after puberty period which was set to 13 years and onwards which suggests they use English as their second or additional language (ESL/EAL).

\subsection{Instruments}

Participants were asked to fill in a survey that consisted of four questionnaires as described below.

\subsubsection{Personal Report of Communication Apprehension (PRCA-24) (McCroskey, 1982)}

The PRCA-24 is widely used to measure CA (Blume et al., 2013) and is reported to be highly reliable (Cronbach's alpha typically reported as $>.90$ ) with very high predictive validity (McCroskey, 1982). This instrument is based on four communication contexts suggested as most relevant to CA (McCroskey \& Beatty, 1984): 1) public speaking, 2) group discussions, 3) speaking in meetings, and 4) interpersonal conversations. The standardised instrument 
composed of 24 statements concerning feelings about communicating with others in four different communication contexts (e.g., "I am tense and nervous while participating in group discussions." or "Certain parts of my body feel very tense and rigid while giving a speech.") was employed. The participants had to indicate the degree to which each statement applied to them by marking the Likert type scale: Strongly Disagree $=1$; Disagree $=2$; Neutral $=3$; Agree $=4$; Strongly Agree $=5$.

\subsubsection{Self-stigma of Academic Help Seeking}

This instrument is a 7-item questionnaire designed by Winograd and Rust (2014). Items include: "My self-confidence would be threatened if I sought academic help." and "I would feel worse about myself if I could not solve my own academic problems on my own." It measures level of self-stigma related to academic help-seeking by using a 5-points Likert scale ranging from strongly agree (1) to strongly disagree (5). The scale generated an alpha of .82 that suggests strong reliability (Winograd \& Rust, 2014).

The scale measurement used for the self-stigma of academic help-seeking questionnaire and PRCA-24 was a 5-point Likert scale where the higher number indicated higher level of selfstigma and CA. Low self-stigma of academic help-seeking and low CA was indicated by mean values less than 2.49, mean values between 2.50 and 3.49 indicated moderate stigmatisation of academic help-seeking while mean values higher than 3.5 were categorised as high.

\subsubsection{Language History Questionnaire, Li, Sepanski and Zhao (2006)}

The standardised language history questionnaire developed by reviewing 41 published studies and has since been used in numerous studies (Li et al., 2013). It contains 6 items asking participants general questions related to the participant's language history and asking them to self-assess their proficiency in each language in terms of reading, spelling and conversing abilities. It includes a mixture of Likert scale based questions and open-ended questions.

\subsubsection{Demographic Information}

Demographic information was collected by asking participants both open-ended and closedended questions. The participants were asked to provide information such as gender, age, academic achievement, year of study and level of English and a country of birth and language spoken at home.

\subsection{Procedure}

Ethical approval for the study was sought from and granted by the Psychology Ethics Committee. The questionnaires were sent via university email ensuring recipients that they were under no obligation to reply to the email. The information sheet clarified the rationale and background of the research to the students and asked for their collaboration and consent to take part in the study. Participation was voluntary and data were treated anonymously and confidentially. Each participant was assigned a 4-digit number as their participant number in case they wished to withdraw their data later. The participants filled in the survey on the online platform Typeform after informed consent was gained. Data were stored in a password protected electronic format on the Typeform platform. 
Data were subjected to descriptive and inferential statistics as reported below. Correlational analyses were run to explore the relationship between self-stigma of academic help-seeking and CA. An ANOVA was employed once for CA and once for self-stigma as dependent variables whereas residency status, age of English acquisition, age and level of study were independent variables.

\section{Results}

Table 1. The Means and the Standard Deviations of the Demographic Variables of the Participants in Relation to the Mean of Communication Apprehension Measured by PRCA-24

\begin{tabular}{llll}
\hline Demographic Variables & & Mean & Standard Deviation (SD) \\
\hline Residency status & Home & 2.64 & 0.69 \\
& EU & 2.94 & 0.76 \\
Age of English & International & 2.71 & 0.76 \\
acquisition & Early & 2.67 & 0.70 \\
& Late (before puberty) & 2.72 & 0.70 \\
Age & Late (after puberty) & 3.30 & 0.73 \\
& 18-20 & 2.83 & 0.77 \\
& $21-24$ & 2.79 & 0.69 \\
Level of study & $25-28$ & 2.54 & 0.80 \\
& 29 and more & 2.49 & 0.74 \\
& Year 1 & 2.93 & 0.63 \\
& Year 2 & 2.86 & 0.75 \\
& Year 3 & 2.60 & 0.69 \\
& Master's & 2.89 & 0.76 \\
& PhD & 2.31 & 0.65 \\
\hline
\end{tabular}

The descriptive statistics as shown in Table 1 indicate that students from the EU report higher level of CA $($ Mean=2.94, $\mathrm{SD}=0.76)$ than international students (Mean=2.71, $\mathrm{SD}=0.76)$ while students from the UK report the lowest $\mathrm{CA}(\mathrm{Mean}=2.64, \mathrm{SD}=0.69)$. In terms of age of acquisition, there was a difference between those that started learning English early, before they turn 5 years old (Mean=2.67, $\mathrm{SD}=0.70$ ) and those that started later yet before the puberty (Mean= 2.72, $\mathrm{SD}=0.70$ ). Students who started learning English after puberty reported higher level of CA (Mean=3.30, $\mathrm{SD}=0.73)$. Age of participants show that the most communication apprehensive were students between age 18-20 (Mean=2.83, $\mathrm{SD}=0.77)$, gradually getting lower in older students, 21-24 (Mean=2.79, $\mathrm{SD}=0.69), 25-28(\mathrm{Mean}=2.54, \mathrm{SD}=0.80)$ and with lowest score reported by mature students aged 29 or more (Mean=2.49, $\mathrm{SD}=0.74$ ). Students' level of study showed that Year 1 students (Mean=2.93, $\mathrm{SD}=0.63$ ) and Master's students (Mean=2.89, $\mathrm{SD}=0.76)$ report higher level of CA compering to students in their year $2($ Mean $=2.86, \mathrm{SD}=0.75)$ with students in their third year $($ Mean=2.60, $\mathrm{SD}=0.69)$ and $\mathrm{PhD}$ students $($ Mean $=2.31, \mathrm{SD}=0.65)$ reporting the lowest levels of $\mathrm{CA}$. 
Table 2. The Means and the Standard Deviations of the Demographic Variables of the Participants in Relation to the Mean of Self-stigma of Academic Help-seeking

\begin{tabular}{llll}
\hline Demographic Variables & & Mean & Standard Deviation (SD) \\
\hline Residency status & Home & 2.23 & 0.81 \\
& EU & 2.23 & 0.81 \\
Age of English & International & 2.03 & 0.58 \\
acquisition & Early & 2.18 & 0.79 \\
& Late (before puberty) & 2.23 & 0.80 \\
Age & Late (after puberty) & 2.28 & 0.78 \\
& $18-20$ & 2.22 & 0.77 \\
& $21-24$ & 2.28 & 0.80 \\
Level of study & $25-28$ & 1.95 & 0.89 \\
& 29 and more & 1.91 & 0.67 \\
& Year 1 & 2.37 & 0.73 \\
& Year 2 & 2.32 & 0.83 \\
& Year 3 & 2.06 & 0.71 \\
& Master's & 2.33 & 0.85 \\
& PhD & 1.70 & 0.63 \\
\hline
\end{tabular}

The descriptive results displayed in Table 2 indicate that the means of self-stigma of academic help-seeking is same for home (Mean=2.23, $\mathrm{SD}=0.81$ ) and $\mathrm{EU}$ students (Mean= 2.23, $\mathrm{SD}=$ 0.81 ). While international students (Mean $=2.03, \mathrm{SD}=0.58$ ) report slightly lower level of selfstigma. With regards to age of English acquisition participants with early acquired language (Mean= 2.18, $\mathrm{SD}=0.79$ ) indicated lower self-stigmatisation of academic help-seeking compering to two other groups, late before puberty (Mean=2.23, $\mathrm{SD}=0.80)$ and late after puberty $($ Mean=2.28, $\mathrm{SD}=0.78)$. Students aged 18-20 (Mean=2.22, $\mathrm{SD}=0.77)$ showed similar but slightly higher level of stigmatisations of help-seeking to students aged 21-24 (Mean=2.28, $\mathrm{SD}=0.80)$. While older groups of students being divided into 25-28 (Mean=1.95, $\mathrm{SD}=0.89$ ) and 29 or more $(\mathrm{Mean}=1.91, \mathrm{SD}=0.67)$ indicated lower self-stigma. Looking at level of study year 1 students reported the highest level of self-stigma (Mean=2.37, $\mathrm{SD}=0.73$ ) with second year $($ Mean $=2.32, \mathrm{SD}=0.83)$ and Master's students (Mean=2.33, $\mathrm{SD}=0.85)$ reporting similar but lower levels of self-stigma. Lower self-stigma of academic help-seeking was reported by third year students (Mean=2.06, $\mathrm{SD}=0.71$ ) with $\mathrm{PhD}$ students (Mean=1.70, $\mathrm{SD}=0.63$ ) to report the lowest self-stigma compering to all other groups.

The data from PRCA-24 and self-stigma of academic help-seeking were subjected to a 3 (Home, EU, International) x 3 (early, late before puberty, late after puberty) x 4 (18-20, 21-24, 25-28, 29 and more) x 5 five (Year 1, Year 2, Year 3, Master's, PhD) factorial ANOVA. The findings showed no significant main effect of student residency status $[F(2,147)=0.41, p=0.66]$, age of English acquisitions $[\mathrm{F}(2,147)=0.12, \mathrm{p}=0.89]$, participants' age $[\mathrm{F}(3,146)=1.14, \mathrm{p}=0.33]$ nor level of study $[\mathrm{F}(4,145)=1.87, \mathrm{p}=0.12]$ on self-stigma of academic help seeking. The results from PRCA-24 showed a marginally significant effect of residency status on CA [F 
$(2,147)=2.84, p=0.06]$. Similarly, the effect of level of study on the level of CA was marginally significant $[\mathrm{F}(4,145)=2.10, \mathrm{p}=0.08]$. ANOVA also showed no significant differences between students' ages $[\mathrm{F}(3,146)=0.99, \mathrm{p}=0.40]$. The age of English acquisition however showed a significant main effect on CA $[\mathrm{F}(2,147)=5.61, \mathrm{p}<0.001]$. Post-hoc Bonferroni t-test showed that students who acquired English late after puberty had significantly higher levels of CA scores than the other two groups: early $[\mathrm{t}(92)=3.30, \mathrm{p}<0.004]$ and late before puberty $[\mathrm{t}(71)=2.96, \mathrm{p}<0.01]$. There was no statistically significant difference found between students who acquired English earlier and those with late acquisition but before puberty ( $\mathrm{p}>$ of 0.1$)$.

The data were also analysed using Pearson correlation coefficient to examine the relationship between mean CA and self-stigma of academic help-seeking among students. The results showed positive statistically significant relationship $(\mathrm{r}=0.436, \mathrm{n}=150, \mathrm{p}=0.0001)$ between the two variables, as shown in the scatterplot (Figure 1). Overall, there was a strong, positive correlation between CA and self-stigma of academic help-seeking. That means that increases in CA were correlated with increases in self-stigma of academic help-seeking.

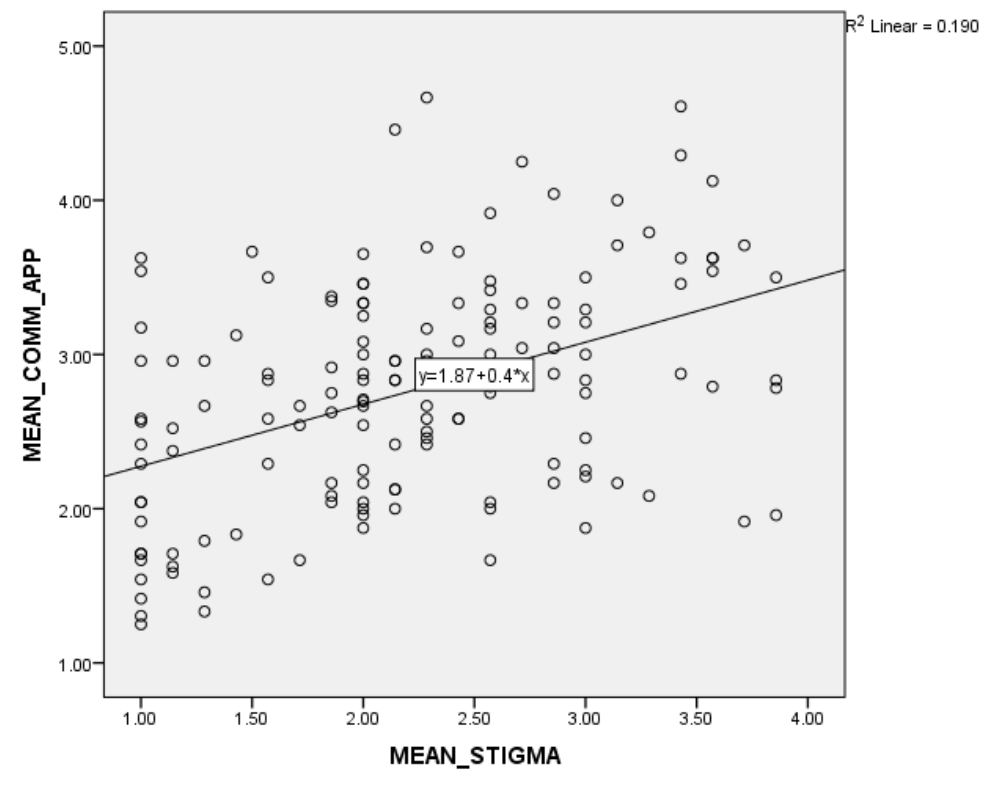

Figure 1. Scatterplot Depicting the Correlation between the Total of Communication Apprehension Measured by PRCA-24 and the Total Self-stigma of Academic Help-seeking

The data were further subjected to a correlation using Pearson correlation to examine the relationship between mean CA and self-stigma of academic help-seeking for the age of English acquisition factor (early, late before puberty and late after puberty). The results indicated a positive statistically significant relationship between self-stigma of academic help-seeking and CA for all three groups; i) 77 participants who acquired English early before 5 years of age $(\mathrm{r}=$ $0.496, \mathrm{p}<0.0001)$, ii) 56 who acquired English later yet before puberty $(\mathrm{r}=0.260, \mathrm{p}<0.05)$ and 
iii) 17 participants who acquired English after puberty $(r=0.829, p<0.0001)$.

\section{Discussion}

The main aim of the study was to examine whether CA and self-stigma of academic helpseeking were linked. Our prediction of a positive relationship was confirmed indicating that students who report higher level of CA have a tendency to struggle with seeking academic help due to self-stigmatisation. This is a significant finding and to the best of our knowledge, the first empirical report of this association between the two concepts, which are related to the individual's self-concept and one's internalised fears (McCroskey, 2009; Winograd \& Rust, 2014). Furthermore, CA, similar to self-stigma, is related to a student's self-esteem (Noor et al., 2015). Students with CA struggle to vocalise their fear, thus keeping it to themselves rather than asking for academic help. Winograd and Rust (2014) reported that students' fear of vocalising their needs and being uncomfortable communicating those needs primarily in a large group such as a lecture among reasons for not seeking help. The pattern of results reported here, is in line with Scott and Wheeless's findings (1977) who found that low CA students sought help three times more often than those with high CA, even though the latter experienced more difficulties with completing given tasks. The pattern of results also confirms the circular and bidirectional relationship between the variables: CA as a form of communication avoidance is linked to avoiding seeking help, which requires communication.

Communication improves only when CA is lessened (Arquero et al., 2007), however, one of the challenges with reducing $\mathrm{CA}$ is the fact that it is rarely recognised by educators. As the findings of the current study showed, high CA students avoid asking for help, which makes it even more difficult for educators to acknowledge students' apprehensiveness. This could be explained by the fact that $\mathrm{CA}$ is often difficult to observe as it is fundamentally personal (Blume et al., 2013) to the same degree as self-stigma which is often linked with low self-esteem (Vogel et al., 2006).

Many HEIs emphasise the importance of training in communication as one of the most effective tools to improve students' communication skills (Allen \& Bourhis, 1996). However, such training can be successful typically with students reporting no or a low level of CA (McCroskey, 1977). Students with high CA as well as those with moderate CA will experience more anxiety by being put 'on the spot'. Therefore, asking students to talk in front of a large audience and including more communication-related tasks in the curriculum without an awareness of the implications and causes of CA, may actually reinforce CA (Blume et al., 2013). The issue is not related to a lack of or poor communication skills but the fear of using them (McCroskey, 1982). The results supported earlier findings that those students who are in real need of help, fail to access available support (Andrade, 2006; Scott \& Wheeless, 1977). As CA is positively correlated with the self-stigma of academic help-seeking, it is imperative for educators to be trained in recognising and interacting with reticent students to avoid possible mental health issues. Approaching and offering academic help to students who need it may reduce CA (McCroskey, 2009). Students who are left on their own without an awareness of any existing help are often afraid to contact unfamiliar services and take part in training. The 
fear of failing in spite of academic help could lead to negative self-judgment and a higher level of self-stigmatisation (Winograd \& Rust, 2014). Therefore, it is important for HEIs help services to provide a more personalised approach to students and familiarise them with the services offered at a very early stage of their education.

The findings reported here suggest that the issue of CA is a global phenomenon affecting students around the world including British university students. The results also revealed that there were differences among students depending on their levels of English. Students who were native English speakers and acquired the language before 5 years old were significantly less communication apprehensive. This is another crucial aspect of the current study as it emphasises the importance of a personalised approach to CA reduction instead of generalising the support offered. As CA was found to be much higher among students who acquired English later in their life, it would be useful to identify and provide additional support for such students in order to reduce negative implications of CA. This study showed that although CA is affecting numerous students on a moderate level, being a student who acquired English later in life creates substantially more anxiety. Anxious students often become overwhelmed and although they need support and academic help as this study showed, they tend to struggle to ask for it. Non-native speakers were found to experience more apprehensiveness as part of language anxiety. This result is in line with Pappamihiel (2001) who reported that language anxiety exists also in mainstream classes despite the high level of English proficiency among students who acquired English after the critical period (Lenneberg, 1967).According to the critical period hypothesis $(\mathrm{CPH})$, learning a language after puberty is much slower and less successful than learning a first language (Lenneberg, 1967).

The present findings indicate that students who acquired English after puberty suffer significantly more CA in English compared to their classmates who acquired English before that period. This is in line with Lillyman and Bennett (2014) findings who found that international students for whom English is not their first language report self-doubt and often loss of self-esteem, which is linked to CA (McCroskey et al., 1985).

What is interesting is that in ESL students CA is related to self-perception of English proficiency (McCroskey et al., 1985; Richmond et al., 2008). However, CA is often unrelated to actual language proficiency (Pappamihiel, 2001). Therefore, due to this negative selfperception, foreign students tend to stick to culturally similar peers, in fear of being socially rejected by native speakers (Andrade, 2006; Pappamihiel, 2001). The results have been upheld by the study conducted by Richmond and colleagues (2008) on Puerto Ricans reporting much higher CA in English than their American fellow students while at the same time reporting low $\mathrm{CA}$ in Spanish as their first language. Lack of involvement and communication from foreign students may be misinterpreted as a cultural issue rather than a linguistic one (Andrade, 2006). It is therefore important to provide support not only to students but also to educators by introducing appropriate training.

Residency was found to influence the level of CA in the current study, with students from EU reporting the highest level of CA followed by international students, while UK students reported the lowest level of CA. Surprisingly, international students were less apprehensive 
than EU students. This could be related to the fact that immigration status does not always reflect language proficiency and that the included international students from countries where English is as an official language! The results further ascertain that linguistics and educational differences are significant contributing factors of CA and it affects diverse nations (Hassal et al., 2000; McCroskey et al., 1985; Richmond et al., 2008). Participants in this study were categorised based on their students' immigration status, which was not linked with their country of birth nor language proficiency. Therefore, it cannot be assumed that immigration status is related to ethnic origin, race or cultural background which was found to significantly influence CA (Winograd \& Rust, 2014). As reported by Andrade (2006), increased anxiety was more common among foreign students who recently arrived at a new country and not necessarily intersected with immigration status. Those findings explained why home students were significantly less apprehensive in comparison to fellow students from different countries.

We also found that first year students were the most anxious across different study years. This could relate to the fact that first year students tend to be more anxious due to the adaptation process and not having established friendships and relationships with tutors (Nayeem et al., 2015). These results are indicative of a deficit in the support system and require further emphasis on early support as the most efficient CA prevention tool and making first year students aware of services. The current findings lend further support to research within language anxiety by finding that the level of study was a significant factor in CA (Elkhafaifi, 2005; Onwuegbuzie et al., 1999). Incidentally, PhD students and third year students were the least communication apprehensive. Although third year students are expected to be more familiar with their university and its services, it was interesting to find similar scores for $\mathrm{PhD}$ students some of whom were new to the university. This finding can be attributable to the fact that $\mathrm{PhD}$ students work semi-independently on their projects without participation in mainstream classes in the UK and tend to be older. According to previous research, level of CA depends on the career pathway chosen, with certain subjects less focused on communication skills (Arquero et al., 2007).

Although the descriptive statistics indicated a trend for higher CA in younger students (18-20 years old) compared to older participants, this difference did not reach statistical significance. In our view, it is important to introduce strategies early in students' academic careers as a prevention tool. The results are in line with one of the first studies on western European students in the UK and Spain that also yielded a null effect for age and CA (Hassall et al., 2000). This is taken as further evidence that effective strategies and actions are required to reduce initially high CA levels (Hassall et al., 2000). Moreover, this has implications for retaining students given that CA is negatively correlated with achievement and may lead to dropping out of certain classes or whole programmes (Croucher, 2017; McCroskey, 1977). Another explanation of insignificant differences in age could be attributed to the nature of experiences in childhood rather than the chronological age itself as reported by McCroskey (2009). This may suggest that the pattern of results regarding age is not as relevant as a student's early experience and their educational background, which could potentially be explored in future work.

Surprisingly, none of the factors outlined in the hypotheses such as residency status, age of 
English acquisition, age and the level of study were found to be significantly different with regards to factors that could potentially influence the level of feeling self-stigmatised due to seeking academic help. These findings suggest that rather than focusing on the level of study or students' age might be more important to promote universities' help services across the university and provide a wider, more approachable, inclusive and visible forms of support. This should perhaps include peer support schemes and group work activities, as being among individuals with equal status (age, the level of study) reduces stigma (Winograd \& Rust, 2014). Additionally, as some students feel more comfortable with their classmates rather than tutors, it is valuable to offer group work activities in order to encourage participation and promote the process of asking questions and, later on, academic help (Thomas et al., 2017).

\subsection{Limitations}

The sample of this study included mainly female participants, namely, 123 (82\%) females versus 27 (18\%) males. Vogel and colleagues (2006) showed that men are less likely to seek help as frequently asking for help seems like a weakness. In a gender dominant culture where males are perceived as independent and able to solve issues on their own, help-seeking can be treated as a threat to masculinity. However, as this sample was biased in terms of gender it would be interesting for future research to investigate the gender differences in the areas of the self-stigmatisation of academic help-seeking. Additionally, participants were students with high grades with $121(81 \%)$ students achieving $1^{\text {st }}$ or 2:1 grades with 24 students achieving 2:2 grade $(16 \%)$ and only 4 students with $3^{\text {rd }}$ grades $(3 \%)$. Interestingly, although CA was still relatively high the results of self-stigma of academic help seeking were much lower among those high-achieving students. Achievement is closely linked to help seeking behaviours with underachieving students having a tendency to avoid help-seeking due to a negative selfjudgement (Karapenick \& Kanpp, 1991; Winograd \& Rust, 2014). Thus, a more balanced and a larger sample could potentially reduce these limitations.

\section{Conclusions and Directions for Future Research}

To conclude, this study is set apart from previous ones in that it firmly establishes the link between CA and self-stigma of academic help-seeking. To the best of the authors' knowledge, this is the first report to do so with implications for adding to the growing body of literature related to maximising students' potential success in HEIs. It also presents results from a nonAmerican sample of university students, broadening the concept in different cultures and demonstrates the importance of personalising and diversifying higher educations' help services.

Even though CA has been studied for decades, further evidence is necessary as the issue is a complex one with huge implications for education and mental well-being. Understanding the relationship between individual differences and CA will help untwine the complex nature of this phenomenon. This research signifies the impact of some of these differences has on CA and how students with differential educational and linguistic backgrounds experience CA differently. Based on the findings reported here, it is important to follow-up with further research to explore whether high CA in English is predictive of high CA in native language in 
non-native English speaking students or whether this is context specific only. Research specifically targeting low achieving students to explore these factors would be of interest from both empirical and applied perspectives.

\section{References}

Abu-Rabia, S. (2004). Teachers' Role, Learners' Gender Differences, and FL Anxiety Among Seventh-Grade Students Studying English as a FL. Educational Psychology, 24(5), 711721. http://dx.doi.org/10.1080/0144341042000263006

Aitken, J., \& Neer, M. (1993). College student question-asking: The relationship of classroom communication apprehension and motivation. Southern Communication Journal, 59(1), 73-81. http://dx.doi.org/10.1080/10417949309372923

Alkhateeb, H. (2014). Reading Anxiety, Classroom Anxiety, Language Motivation, Reader Self-Perception, and Arabic Achievement of Arab-American Students Learning Arabic as a Second Language. Psychological Reports, 115(3), 918-931. http://dx.doi.org/10.2466/11.pr0.115c27z6

Allen, M., \& Bourhis, J. (1996). The relationship of communication apprehension to communication behavior: A meta-analysis. Communication Quarterly, 44(2), 214-226. http://dx.doi.org/10.1080/01463379609370011

Andrade, M. (2006). International students in English-speaking universities. Journal of Research in International Education, 5(2), 131-154. http://dx.doi.org/10.1177/1475240906065589

Arquero, J., Hassall, T., Joyce, J., \& Donoso, J. (2007). Accounting Students and Communication Apprehension: A Study of Spanish and UK Students. European Accounting Review, 16(2), 299-322. http://dx.doi.org/10.1080/09638180701391337

Bijani, H., \& Sedaghat, A. (2016). The Application of Communication Strategies by Students with Different Levels of Communication Apprehension in EFL Context. Theory and Practice In Language Studies, 6(2), 366-371. http://dx.doi.org/10.17507/tpls.0602.19

Blume, B., Baldwin, T., \& Ryan, K. (2013). Communication Apprehension: A Barrier to Students' Leadership, Adaptability, and Multicultural Appreciation. Academy of $\begin{array}{llll}\text { Management Learning \& } \quad \text { Education, } & 12(2), & 158-172 .\end{array}$ http://dx.doi.org/10.5465/amle.2011.0127

Brown, L. (2008). Language and anxiety: An ethnographic study of international postgraduate students. Evaluation \& Research in Education, 21(2), 75-95. http://dx.doi.org/10.1080/09500790802152167

Byrne, M., Flood, B., \& Shanahan, D. (2012). A Qualitative Exploration of Oral Communication Apprehension. Accounting Education, 21(6), 565-581. http://dx.doi.org/10.1080/09639284.2012.725636 
Chomsky, C. (1972). Stages in Language Development and Reading Exposure. Harvard Educational Review, $42(1)$, $1-33$. http://dx.doi.org/10.17763/haer.42.1.h781676h28331480

Croucher, S. (2017). Bringing International Perspectives to the Communication Curriculum in an Era of Globalization. Journal of Intercultural Communication Research, 46(3), 295296. http://dx.doi.org/10.1080/17475759.2017.1308458

Cummins, J. (1979). Cognitive/Academic language proficiency, linguistic interdependence, the optimum age question and some other matters. Working Papers on Bilingualism, (19), 197-202. Retrieved from https://eric.ed.gov/?id=ED184334

Deasy, C., Coughlan, B., Pironom, J., Jourdan, D., \& Mannix-McNamara, P. (2016). Psychological distress and help seeking amongst higher education students: findings from a mixed method study of undergraduate nursing/midwifery and teacher education students in Ireland. Irish Educational Studies, 35(2), 175-194. http://dx.doi.org/10.1080/03323315.2016.1146157

Dewaele, J. M., \& Thirtle, H. (2009). Why do some young learners drop foreign languages? A focus on learner-internal variables. International Journal of Bilingual Education and Bilingualism, 12(6), 635-649. http://dx.doi.org/10.1080/13670050802549656

Dewaele, J., \& Shan Ip, T. (2013). The link between Foreign Language Classroom Anxiety, Second Language Tolerance of Ambiguity and Self-rated English proficiency among Chinese learners. Studies in Second Language Learning and Teaching, 3(1), 47-66. http://dx.doi.org/10.14746/ssllt.2013.3.1.3

Donovan, L., \& MacIntyre, P. (2004). Age and sex differences in willingness to communicate, communication apprehension, and self-perceived competence. Communication Research Reports, 21(4), 420-427. http://dx.doi.org/10.1080/08824090409360006

Dunn, K., Rakes, G., \& Rakes, T. (2014). Influence of academic self-regulation, critical thinking, and age on online graduate students' academic help-seeking. Distance Education, 35(1), 75-89. http://dx.doi.org/10.1080/01587919.2014.891426

Elkhafaifi, H. (2005). Listening Comprehension and Anxiety in the Arabic Language Classroom. The Modern Language Journal, 89(2), 206-220. $\mathrm{http} / / \mathrm{dx}$.doi.org/10.1111/j.1540-4781.2005.00275.x

Garcia de Blakeley, M., Ford, R., \& Casey, L. (2017). Second language anxiety among Latino American immigrants in Australia. International Journal of Bilingual Education and Bilingualism, 20(7), 759-772. http://dx.doi.org/10.1080/13670050.2015.1083533

Gregersen, T., \& Horwitz, E. K. (2002). Language Learning and Perfectionism: Anxious and Non-Anxious Language Learners' Reactions to Their Own Oral Performance. The Modern Language Journal, 86(4), 562-570. http://dx.doi.org/10.1111/1540-4781.00161

Hassall, T., Joyce, J., Ottewill, R., Arquero, J., \& Donoso, J. (2000). Communication apprehension in UK and Spanish business and accounting students. Education Training, 
42(2), 93-100. http://dx.doi.org/10.1108/eum0000000005351

Horwitz, E. K., Horwitz, M. B., \& Cope, J. (1986). Foreign Language Classroom Anxiety. The Modern Language Journal, 70(2), 125.

Karabenick, S. A., \& Knapp, J. R. (1988). Help seeking and the need for academic assistance. Journal of Educational Psychology, 80(3), 406-408. http://dx.doi.org/10.1037/00220663.80.3.406

Krashen, S., \& Harshman, R. (1972). Lateralization and the critical period. The Journal of the Acoustical Society of America, 52(1A), 174. http://dx.doi.org/10.1121/1.1982096

Lenneberg, E. H. (1967). The biological foundations of language. Hospital Practice, 2(12), 5967. http://dx.doi.org/10.1080/21548331.1967.11707799

Li, P., Sepanski, S., \& Zhao, X. (2006). Language history questionnaire: A Web-based interface for bilingual research. Behavior Research Methods, 38(2), 202-210. http://dx.doi.org/10.3758/bf03192770

Lillyman, S., \& Bennett, C. (2014). Providing a positive learning experience for international students studying at UK universities: A literature review. Journal of Research in International Education, 13(1), 63-75. http://dx.doi.org/10.1177/1475240914529859

McCroskey, J. (1970). Measures of communication-bound anxiety. Speech Monographs, 37(4), 269-277. http://dx.doi.org/10.1080/03637757009375677

McCroskey, J. (1977). Classroom consequences of communication apprehension. Communication Education, 26(1), 27-33. http://dx.doi.org/10.1080/03634527709378196

McCroskey, J. (1982). An introduction to rhetorical communication (4th ed.). Englewood Cliffs, N.J.: Prentice-Hall.

McCroskey, J. C. (2009). Communication apprehension: What have we learned in the last four decades. Human Communication, 12(2), 179-187.

McCroskey, J., \& Andersen, J. (1976). The relationship between communication apprehension and academic achievement among college students. Human Communication Research, 3(1), 73-81. http://dx.doi.org/10.1111/j.1468-2958.1976.tb00506.x

McCroskey, J. C., Gudykunst, W. B., \& Nishida, T. (1985). Communication apprehension among Japanese students in native and second language. Communication Research Reports, 2(1). 11-15.

McCroskey, J., \& Beatty, M. (1984). Communication apprehension and accumulated communication state anxiety experiences: A research note. Communication Monographs, 51(1), 79-84. http://dx.doi.org/10.1080/03637758409390185

Newman, R. S. (2002). How Self-Regulated Learners Cope with Academic Difficulty: The Role of Adaptive Help Seeking. Theory into Practice, 41(2), 132-138. http://dx.doi.org/10.1207/s15430421tip4102_10 
Noor, A. M., Rafek, M., Khalid, P. Z. M., \& Mohammad, R. (2015). Communication Apprehension In Language Learning: Is It Serious? International Journal of Arts \& Sciences, 8(2), 311-320.

Onwuegbuzie, A. J., Bailey, P., \& Daley, C. E. (1999). Factors associated with foreign language anxiety. Applied Psycholinguistics, 20(2), 217-239. https://doi.org/10.1017/s0142716499002039

Pappamihiel, N. E. (2001). Moving from the ESL classroom into the mainstream: An investigation of English language anxiety in Mexican girls. Bilingual Research Journal, 25(1-2), 31-38. http://dx.doi.org/10.1080/15235882.2001.10162783

Pearson, J., \& West, R. (1991). An initial investigation of the effects of gender on student questions in the classroom: Developing a descriptive base. Communication Education, 40(1), 22-32. http://dx.doi.org/10.1080/03634529109378823

Perrine, R., Lisle, J., \& Tucker, D. (1995). Effects of a Syllabus Offer of Help, Student Age, and Class Size on College Students' Willingness to Seek Support from Faculty. The Journal of Experimental Education, 64(1), 41-52. http://dx.doi.org/10.1080/00220973.1995.9943794

Rahmani, D., \& Croucher, S. (2017). Minority Groups and Communication Apprehension. Journal of Intercultural Communication, 2017(43).

Raman, I., \& Y1ldı,, Y. (2019). Orthographical, phonological, and morphological challenges in language processing: The case of bilingual Turkish-English speakers. In B. Christiansen \& E. Turkina (Eds.), Advances in linguistics and communication studies (ALCS). Applied psycholinguistics and multilingual cognition in human creativity (p. 130). Information Science Reference/IGI Global. https://doi.org/10.4018/978-1-52256992-3.ch001

Raphael, T., \& Pearson, P. (1985). Increasing Students' Awareness of Sources of Information for Answering Questions. American Educational Research Journal, 22(2), 217-235. http://dx.doi.org/10.2307/1162841

Rasakumaran, A., \& Devi, S. I. (2017). Oral communication apprehension among freshmen: a case in faculty of medicine. Journal of Human Capital Development (JHCD), 10(1). 1932 .

Richmond, V., McCroskey, J., McCroskey, L., \& Fayer, J. (2008). Communication Traits in First and Second Languages: Puerto Rico. Journal of Intercultural Communication Research, 37(2), 65-73. http://dx.doi.org/10.1080/17475750802533331

Ryan, A., Gheen, M., \& Midgley, C. (1998). Why do some students avoid asking for help? An examination of the interplay among students' academic efficacy, teachers' socialemotional role, and the classroom goal structure. Journal of Educational Psychology, 90(3), 528-535. http://dx.doi.org/10.1037//0022-0663.90.3.528

Sabri, U., \& Qin, T. (2014). Communication Apprehension among Nilai College Students. 
Advances in Language and Literary Studies, 5(5), 46-49. http://dx.doi.org/10.7575/aiac.alls.v.5n.5p.46

Scott, M. D., \& Wheeless, L. R. (1977). Instructional communication theory and research: An overview. Annals of the International Communication Association, 1(1), 495-511. http://dx.doi.org/10.1080/23808985.1977.11923702

Semmar, Y. (2010). First Year University Students and Language Anxiety: Insights into the English Version of the Foreign Language Classroom Anxiety Scale. International Journal of Learning, 17(1), 81-93. https://doi.org/10.18848/1447-9494/cgp/v17i01/46805

Thomas, S., Tewell, E., \& Willson, G. (2017). Where Students Start and What They Do When They Get Stuck: A Qualitative Inquiry into Academic Information-Seeking and HelpSeeking Practices. The Journal of Academic Librarianship, 43(3), 224-231. http://dx.doi.org/10.1016/j.acalib.2017.02.016

Vogel, D. L., Wade, N. G., \& Haake, S. (2006). Measuring the self-stigma associated with seeking psychological help. Journal of Counseling Psychology, 53(3), 325-337. http://dx.doi.org/10.1037/0022-0167.53.3.325

Williams, T. R. (2005). Exploring the Impact of Study Abroad on Students' Intercultural Communication Skills: Adaptability and Sensitivity. Journal of Studies in International Education, 9(4), 356-371. http://dx.doi.org/10.1177/1028315305277681

Winograd, G., \& Rust, J. P. (2014). Stigma, Awareness of Support Services, and Academic Help-Seeking Among Historically Underrepresented First-Year College Students. The Learning Assistance Review, 19(2), 19-44.

\section{Copyright Disclaimer}

Copyright for this article is retained by the author(s), with first publication rights granted to the journal.

This is an open-access article distributed under the terms and conditions of the Creative Commons Attribution license (http://creativecommons.org/licenses/by/3.0/). 